\title{
Some observations on the spread-winged agonistic displays of the Indian Eagle Owl Bubo bengalensis (Franklin, 1831)
}

\author{
M. Eric Ramanujam
}

Principal Investigator (Faunistics), Pitchandikulam Bioresource Centre / Pitchandikulam Forest Consultants, Pitchandikulam Forest, Auroville, Tamil Nadu 605101, India

Email: ericramanujam@yahoo.co.in

Abstract: In a study on the Indian Eagle Owl Bubo bengalensis in southern India, three morphologically distinct spread- winged displays have been identified - viz., intimidatory display, threat display and intermediate agonistic displays. While the first and last displays were employed in inter-specific encounters, the threat display was used against conspecifics in the wild. These displays have not been observed to progress from one to the other, but it may be possible that they stem from a common evolutionary root. The inter-specific intimidatory behavior of a female in defense of its young is also presented.

Keywords: Agonistic behavior, inter- and intra-specific behavior. intimidatory display, ritual display, threat display, transition agonistic displays.

In spite of earlier work on the spread-winged agonistic displays of the Indian Eagle Owl Bubo bengalensis (Ramanujam 2000, 2003, 2004, 2007) there still remains an element of doubt regarding the variations between these ritualistic postures. A perusal of published literature on the species and the closely related Eurasian Eagle Owl Bubo bubo disclosed the fact that due to the lack of

Date of publication (online): 26 August 2010

Date of publication (print): 26 August 2010

ISSN 0974-7907 (online) | 0974-7893 (print)

Editor: Rajah Jayapa

Manuscript details:

Ms \# 02249

Received 03 July 2009

Final revised received 02 August 2010

Finally accepted 04 August 2010

Citation: Ramanujam, M.E. (2010). Some observations on the spreadwinged agonistic displays of the Indian Eagle Owl Bubo bengalensis (Franklin, 1831). Journal of Threatened Taxa 2(9): 1147-1152.

Copyright: (c) M. Eric Ramanujam 2010. Creative Commons Attribution 3.0 Unported License. JoTT allows unrestricted use of this article in any medium for non-profit purposes, reproduction and distribution by providing adequate credit to the authors and the source of publication.

Acknowledgements: I wish to thank the Principal Chief Conservator of Forests and Head of Forest Force for granting permission to work in Nanmanglam Reserve Forest. I am indebted to A. Lakshmikantan whose photographic work, patience and stoicism resulted in the ethograms recorded. I am also thankful to Dr. T. Murugavel and M. Saravanan for supplying the photographs of the intimidatory and threat displays.

\section{OPEN ACCESS | FREE DOWNLOAD CC (1) С}

standardized nomenclature of behavioral traits there is a great deal of ambiguity where causations and functions are poorly understood - for example, it was not at all certain what was meant by "distraction displays in January near the nest" (Vyas 1996) and "aggressive posture" at the age of 15 days (Penteriani et al. 2004). Though I conjencture that the first could be the intermediate agonistic display indulged in by and parents in defence of their young and the second, the intimidatory display of young, there still remains a sense of ambiguity. In fact the lacuna of detailed ethograms and their recognisation is a fundamental issue and I too have been guilty of misrepresentation - viz., when investigating the behavior of parents in defense of nestlings in and around Puducherry, I made the fundamental error of not recognizing the intermediate phase and called it a "female intimidatory display" (Ramanujam 2004) and again confused it with the intimidatory display employed by the young (Ramanujam 2007).

The lack of standardized nomenclature, ethograms and recognition pertaining to these behavioral traits is unfortunate since, even during the early days of ethological investigation, ritualized displays had been recognized to be key features that can shed light on phylogenetic relationships, and since owls had been proven to be a monophyletic group due to the similarities in their displays (Ramanujam 2000, 2003) these are paramount to understanding their behavior and links to evolutionary biology.

This document simply aims to conclusively provide proof of the morphological differences between the threat and intimidatory displays, call hitherto unrecognized intermediate phases to attention and attempt to standardise nomenclature concerning them. Incidentally, it also presents reactions of parent birds in response to human approach of a nest with young which is an update of an earlier exercise.

Methods: This is the output of field observations, especially during the breeding season of Bubo bengalensis since 1997.

The area of inquiry began in and around the Union Territory of Puducherry (formerly Pondicherry) in the ravines extending from Kalapet $\left(12^{\circ} 01^{\prime} \mathrm{N} \& 7^{\circ} 51^{\prime} \mathrm{E}\right)$ near the seashore, south-westwards through the Auroville 


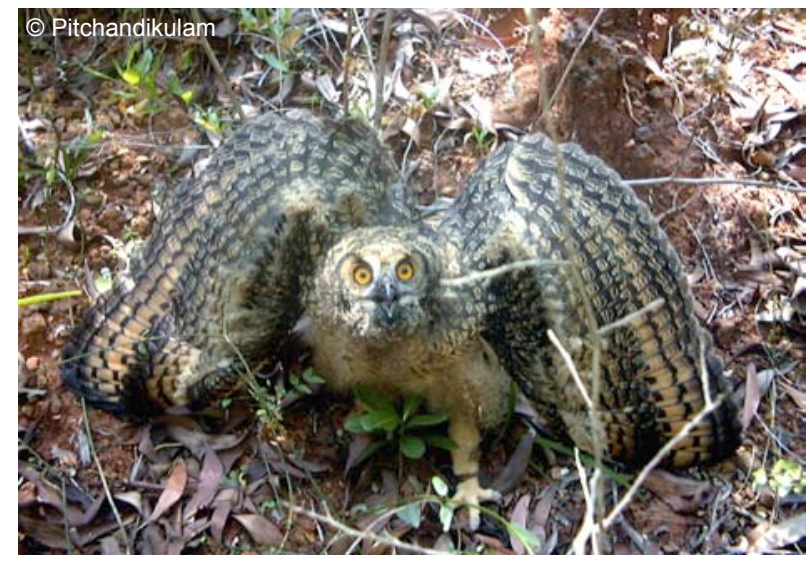

Image 1. Frontal view of intimidatory display of young Bubo bengalensis. Note that the wings are inverted and perpendicular to the ground.

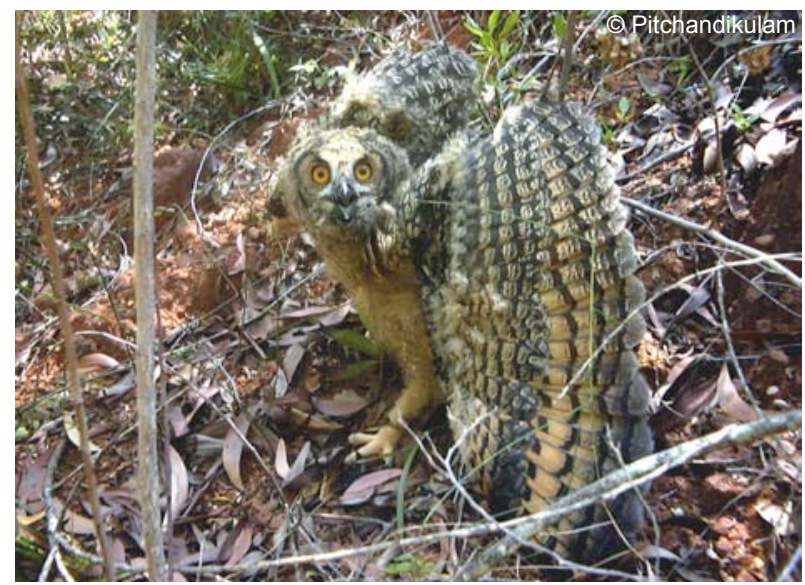

Image 2. Side view of intimidatory display of young Bubo bengalensis to emphasise the inverted and perpendicular slant of wings.

Plateau to the Aranya-Merveille area (11058'N \& 7946'E) adjacent to Ousteri Lake. This area is deeply scoured with innumerable ravines and gullies and these provide ideal habitats for Bubo bengalensis. Five breeding pairs and their young were intermittently observed since 1997, especially at their nests. Twelve nesting instances were intensely observed, from the time the chicks hatched to the time they branched out, which took a month or so. These observations alone accounted for over 5,000 field hours. Ten approaches to the nests were made - the results of nine have been reported earlier (Ramanujam 2004) and the last has been reported along with photographic documentation here. In addition, bird watching sessions were concurrently held with pellet gathering exercises which was approximately 10-12 days a month for a couple of hours - accounting for over 1,200 field hours.

Recently observations were also made at

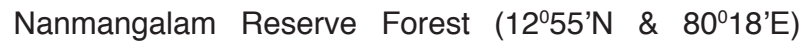
on the outskirts of Chennai adjacent to the Tambaram

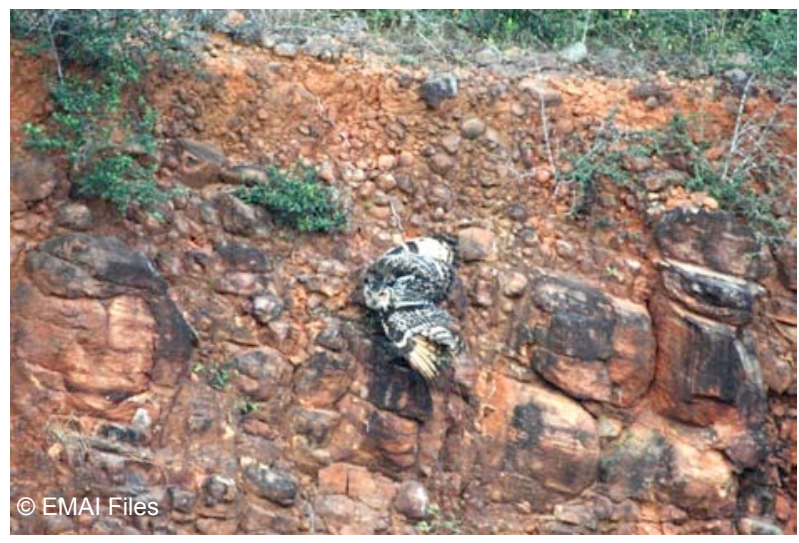

Image 3. Threat display in intra-specific circumstance (the other owl was outside the frame and to the left). Note that the wings are held flat and parallel to the surface on which it perched. The display was more pronounced before the observer distracted it, resulting in it turning and folding its wings slightly at the wrists. This is the only photograph we have been able to procure of the display - it is so hard to come by under normal circumstances (I have personally observed the display only 25 times since 1997 when I started work on the species, and that too at dusk and in bad light), that to encounter it during the day was a stroke of luck and to photograph it even more so.

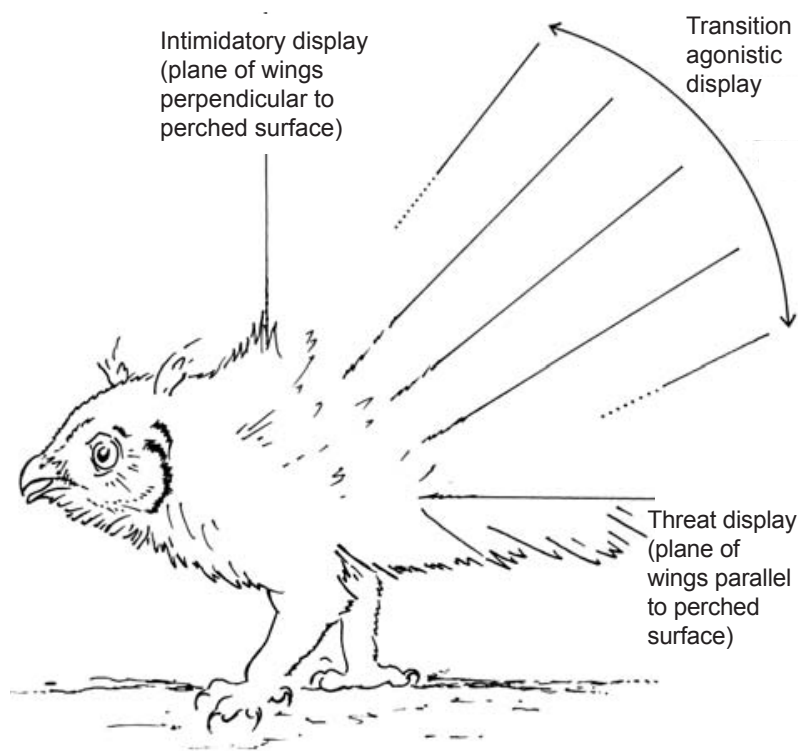

Figure 1. Representation of plane of wings in relation to the perched surface for the spread-winged displays of Bubo bengalensis.

- Velacheri Road (at a distance of approximately $7 \mathrm{~km}$ from the latter). The main path to the north leads to five disused water filled granite quarries. These are occupied by three pairs of Bubo bengalensis. The nests could not be approached closely as the steep sides made access almost impossible. Observations were made for approximately 120 field hours.

Though a number of subjects were studied, ethograms 
Table 1. The observed spread-winged displays of Bubo bengalensis in the wild

\begin{tabular}{|c|c|c|c|c|c|c|}
\hline Sno & Display & Morphological description & $\begin{array}{l}\text { Employed } \\
\text { by }\end{array}$ & $\begin{array}{l}\text { Observed } \\
\text { stimulus }\end{array}$ & Observed function & Remarks \\
\hline 1 & $\begin{array}{l}\text { Intimidatory } \\
\text { Display } \\
\text { (Images } 1 \\
\& 2 \text { ) }\end{array}$ & $\begin{array}{l}\text { A display with the face of the wings } \\
\text { held perpendicular to the perched } \\
\text { substrate and bent at the elbow } \\
\text { and wrist. On being confronted by } \\
\text { intruders, the owl stared fixedly at } \\
\text { them, leant forward, swayed from } \\
\text { foot to foot, swelled feathers to their } \\
\text { full extend and opened the wings } \\
\text { outwards. Loud hissing and bill } \\
\text { clapping enhanced the appearance } \\
\text { of ferocity }\end{array}$ & $\begin{array}{l}\text { Young } \\
\text { over } 15 \\
\text { day's old }\end{array}$ & $\begin{array}{l}\text { Human } \\
\text { approach }\end{array}$ & $\begin{array}{l}\text { The action was a bluff, } \\
\text { the intent being to keep } \\
\text { intruders at bay. A } \\
\text { diversionary tactic which } \\
\text { allowed the young to } \\
\text { make good their escape } \\
\text { either by running or flying } \\
\text { away }\end{array}$ & $\begin{array}{l}\text { An inter-specific } \\
\text { display used to } \\
\text { deter intruders }\end{array}$ \\
\hline 2 & $\begin{array}{l}\text { Threat } \\
\text { Display } \\
\text { (Image 3) }\end{array}$ & $\begin{array}{l}\text { A display with the face of the wings } \\
\text { held parallel to the perched substrate }\end{array}$ & Adults & $\begin{array}{l}\text { Used against } \\
\text { conspecifics } \\
\text { - viz., } \\
\text { territorial } \\
\text { male against } \\
\text { intruders and } \\
\text { females to } \\
\text { repel males } \\
\text { outside the } \\
\text { breeding } \\
\text { season }\end{array}$ & $\begin{array}{l}\text { To deter conspecifics. } \\
\text { This was no bluff, the } \\
\text { intent being to scare } \\
\text { off the other owl, and if } \\
\text { stimulus persisted, the } \\
\text { displaying bird would } \\
\text { attack unhesitatingly }\end{array}$ & $\begin{array}{l}\text { An intra-specific } \\
\text { display used against } \\
\text { other owls in the } \\
\text { wild }\end{array}$ \\
\hline 3 & $\begin{array}{l}\text { Intermediate } \\
\text { agonistic } \\
\text { displays } \\
\text { (Images } 7 \\
\& 8 \text { ) }\end{array}$ & $\begin{array}{l}\text { These are displays with the wings } \\
\text { held intermediate between the } \\
\text { intimidatory and threat displays. } \\
\text { Many intensity phases exist, often } \\
\text { with one wing behaving differently } \\
\text { from the other. These are not } \\
\text { transition phases between the } \\
\text { intimidatory and threat displays, } \\
\text { and have never been observed } \\
\text { to progress from one to the other. } \\
\text { In fact they have their own set of } \\
\text { progression (as is evident from } \\
\text { Images 4-11) }\end{array}$ & $\begin{array}{l}\text { Brooding } \\
\text { female in } \\
\text { defence } \\
\text { of nest / } \\
\text { young }\end{array}$ & $\begin{array}{l}\text { Human } \\
\text { approach of } \\
\text { nest }\end{array}$ & To deter intruders & $\begin{array}{l}\text { These are inter- } \\
\text { specific displays } \\
\text { which were earlier } \\
\text { confused with the } \\
\text { intimidat-ory display } \\
\text { (Ramanu- } \\
\text { jam 2004, 2007). } \\
\text { Now with detailed } \\
\text { photogra-phic } \\
\text { ethogra-ms their } \\
\text { morphol-ogical } \\
\text { differen-ces have } \\
\text { come to light }\end{array}$ \\
\hline
\end{tabular}

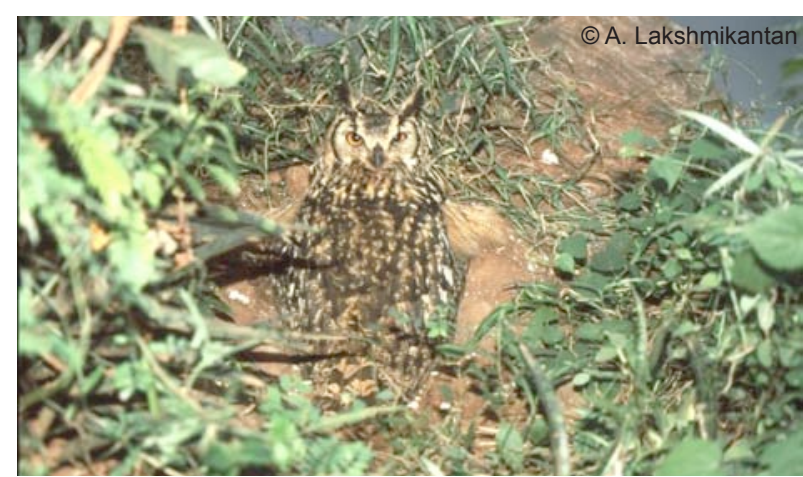

Image 4. Female on nest. Note the sleeked plumage (Human range ca. 28-30 m).

of only a few could be satisfactorily recorded and this photographic evidence is presented here.

Results: Three distinct spread-winged agonistic displays were observed - viz., the intimidatory display (Images 1 \& 2), threat display (Image 3) and intermediate agonistic displays (Images $7 \& 8$ ) which have only now been conclusively recorded. For further details refer Table 1 and Fig. 1.

Prior to this only two spread-winged agonistic

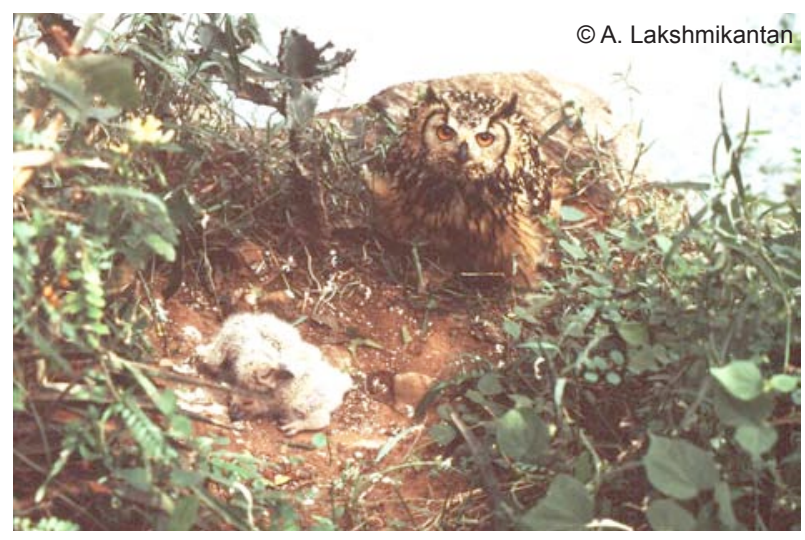

Image 5. Brooding female left the nest and began erecting body plumage, hissing, bill clapping and giving the alarm call (Human distance from nest ca. 24-30 m).

displays in Bubo bengalensis had been recognised. Now conclusive proof has been presented of a series of intermediatory displays employed by a female to human approach to its nest and young.

A brief description of the individual components of behavior as recorded in this female in order of occurrence, is described below: 


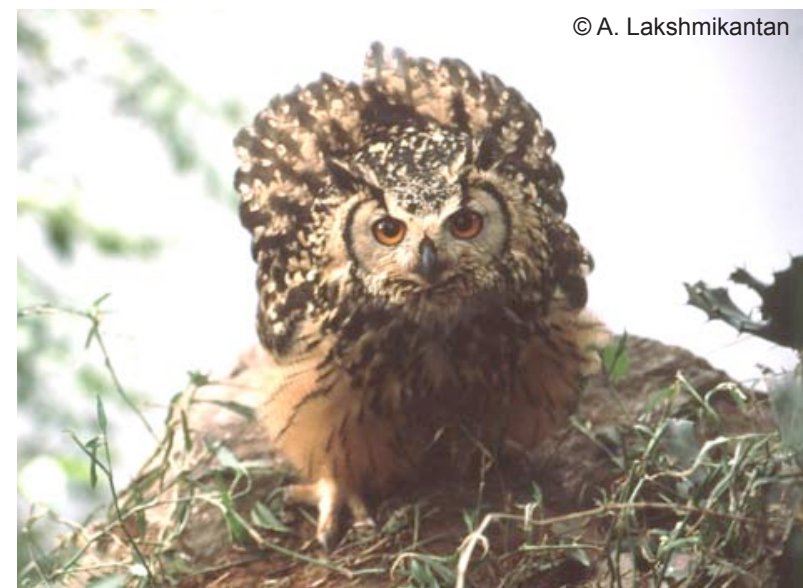

Image 6. Close-up of ruffled plumage.

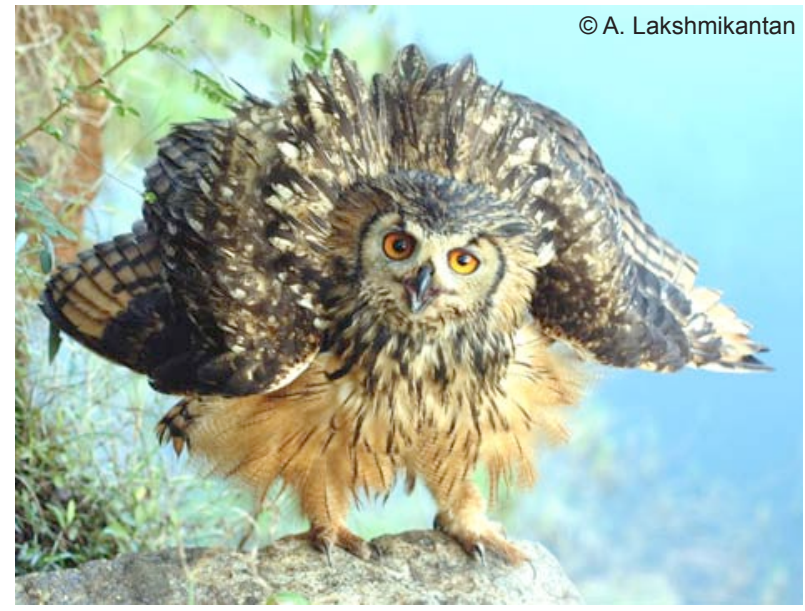

Image 8: Another phase of the transition agonistic display. This photograph shows another facet $-i$.e. the left wing behaving differently from the right wing. Whereas the right wing (left to the observers) shows a strong tendency towards the intimidatory display, the left wing shows a leniency towards the threat display. It is possible that in a state of strong conflicting emotions such phenomena are common.

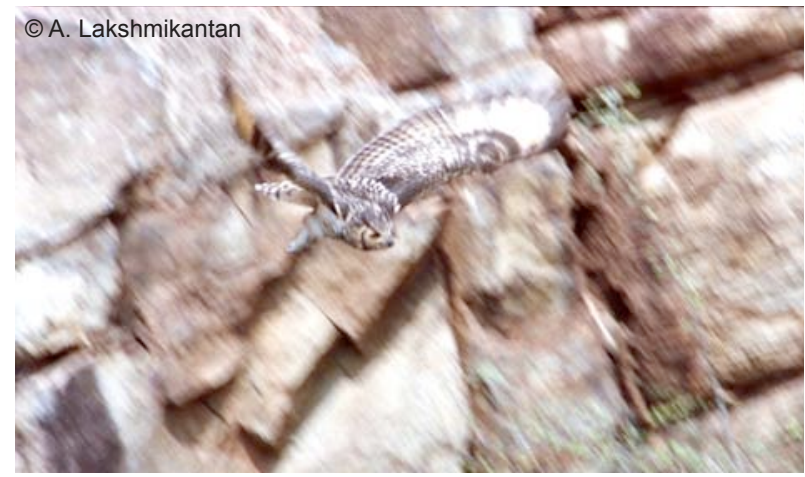

Image 10. Male flew in to join female.

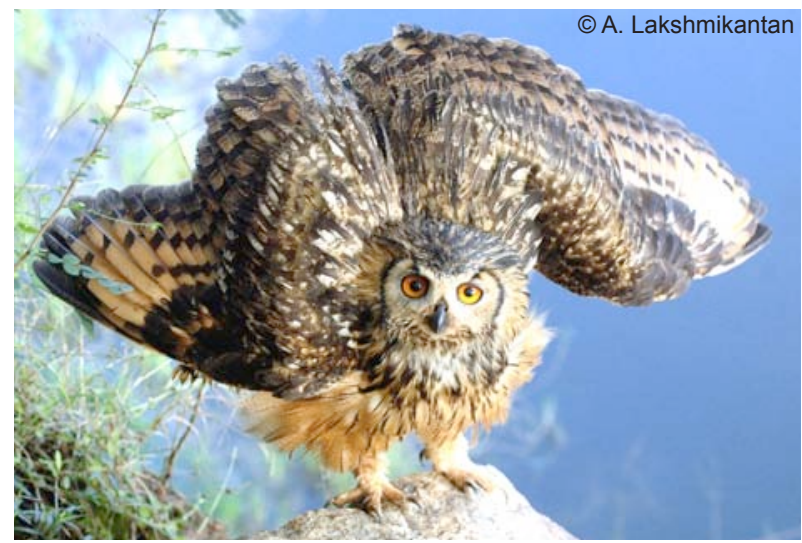

Image 7. Transition agonistic display. Note that the wings are neither parallel nor perpendicular to the ground (Human distance from the nest ca. 10-24 m).

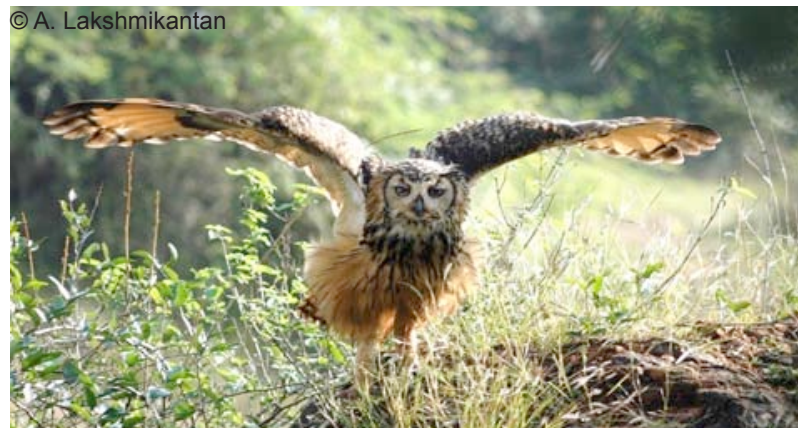

Image 9. Wing flapping (Human distance from nest $<10 \mathrm{~m}$ ).

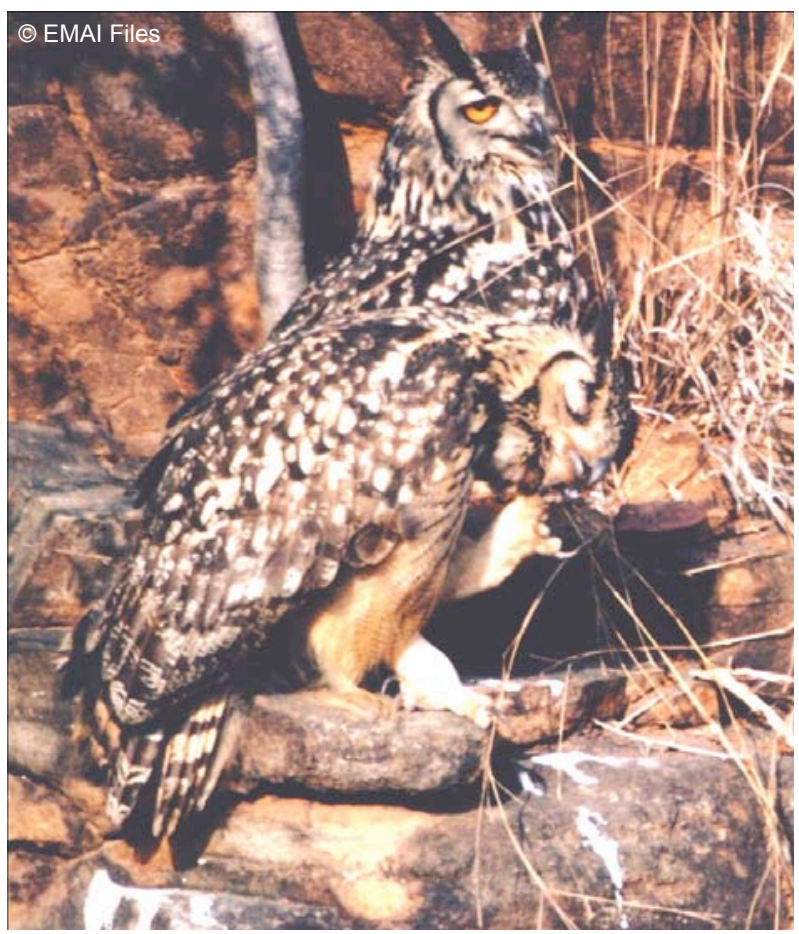

Image 11. Head scratching and preening (the male is in the background). 

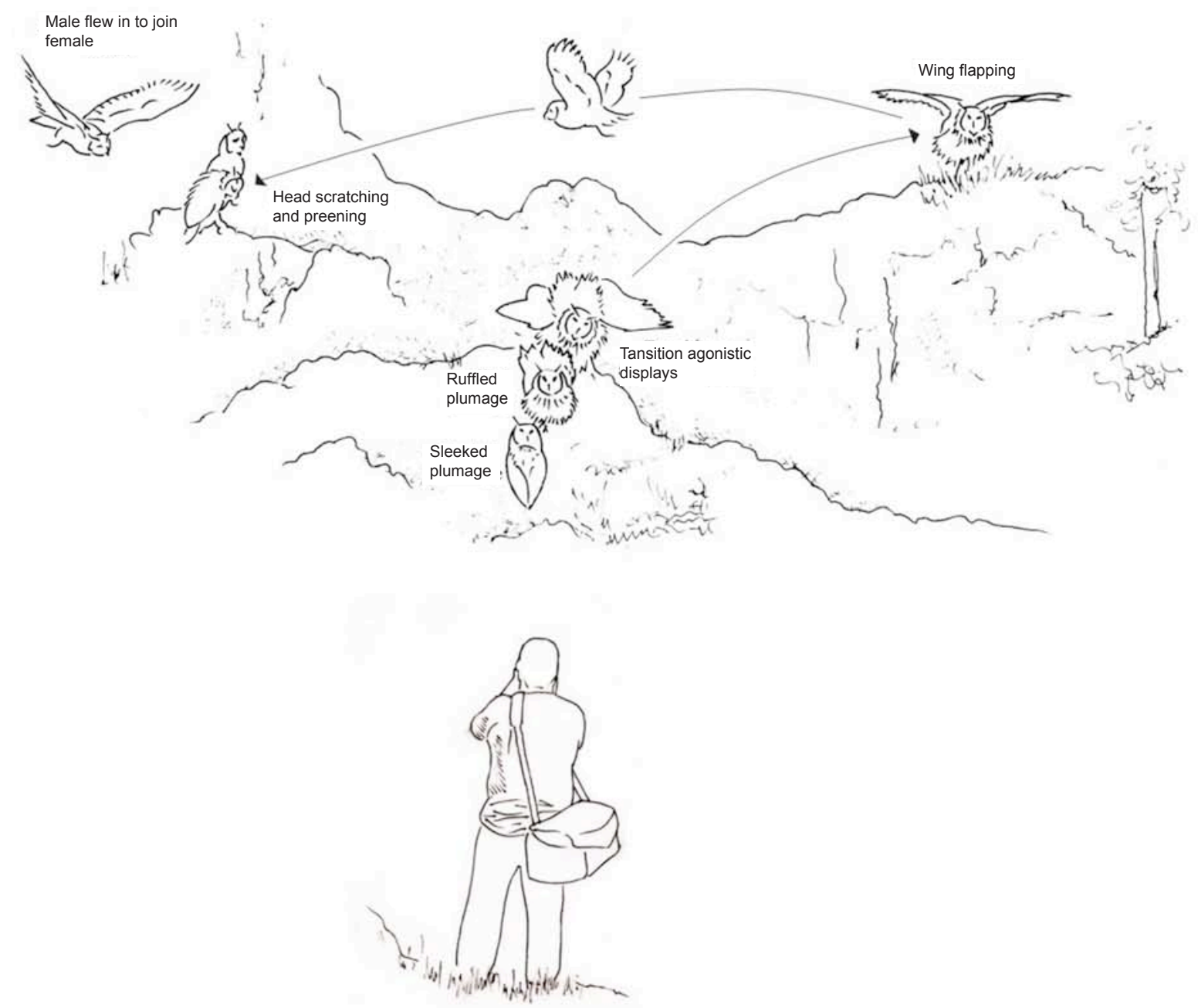

Figure 2. Simplified conceptual representationof brooding female's behaviour in response to human approach of the nest site (for ethograms refer images 4-11).

1. Sleeked plumage (Image 4): A concealing attitude adopted when incubating and brooding by the female. So effective was the camouflage that crows flying overhead never once detected it.

2. Alarm call: A startling loud harsh keaou-kak-kak. It was uttered in the course of erecting the body plumage along with hissing and bill clapping. It persisted throughout the time the observers were in the vicinity.

3. Ruffled plumage (Images $5 \& 6$ ): The incubating female rose off the nest, stared unblinkingly at the intruder and simultaneously erected its body plumage making it appear larger than normal. All the time it uttered the alarm call. In addition, loud hissing and bill clapping accompanied this and the next display.

4. Transition agonistic displays (Images 7 \& 8): The subject swelled its feathers to their full extent and opened its wings - thus making it appear many times its usual size. This was not the full intensity intimidatory position adopted by young owls (where the wings are held perpendicular to the ground) or the threat display (where the wings are held parallel to the ground), but intermediate between them. During the displays the wings kept fluctuating between the two full intensity types without once actually assuming them and one side often behaved differently from the other. It is theorized that the urge to defend its young was in conflict with its desire to flee, hence these intermediate transition phases. The angle of the wings and their relativity to the ground should be noted and compared with Images 1 \& 2 which show the intimidatory display as employed by young Bubo bengalensis in interspecific encounters, as well as Image 3 which shows the threat display as employed by the adults in intra-specific encounters.

5. Wing flapping (Image 9): Once the subject was seen to flap its wings after flying away to the other side of the canyon. Maybe it was a displacement activity.

6. Head scratching and preening (Image 11): These were definitely displacement activities as they were more stereotyped than normal and directed towards the more conspicuous body parts. 
On one occasion the male flew in to join the female (Images 10 \& 11).

For further details refer to Fig. 2 and Images 4-11.

Discussion: Since they are all spread-winged displays, the ritualized transition agonistic displays show a semblance of relationship to both the intimidatory display exhibited by the young in inter-specific encounters and the threat display by adults in intra-specific encounters. This is illuminating, in the sense that these could be linkages between the individual components whose evolutionary antecedents remain unclear at this point of time. One thing must be made clear: it is not suggested that the ritualized displays progress form threat to transition to intimidatory or vice versa and no evidence of such progressions were observed in the wild. But it may be possible that such linkages do exist, and in the future under controlled conditions, more light could be shed on the phenomena.

In comparision to an earlier study on inter-specific behavior of adult Bubo bengalensis, it was observed that each breeding pair behaved differently (Ramanujam 2004) and this phenomenon has been observed during the last instance also. The phenomenon of differential responses as employed by adult owls in defence of their young is in stark contrast to the displays of the young themselves which followed an innate standard behavioral pattern irrespective of the conditions (Ramanujam 2003, 2007). The differential response of adults in inter- specific encounters could be influenced by environment, conditioning and learning, or a combination of these. More tests are necessary to unravel the issues.

At this stage I have simply recorded ethograms in the wild which could be of use to extension workers with an interest in ethology / evolutionary biology of owls in particular and other species in general

\section{REFERENCES}

Penteriani, V., M.M. Delgado, C. Maggio, A. Aradis \& F. Sergio (2005). Development of chicks and predispersal behavior of young in the Eagle Owl Bubo bubo. Ibis 147: 155-168.

Ramanujam, M.E. (2000). An attempt to rationalize on the vocalizations and displays of captive Indian Eagle Owls Bubo bubo bengalensis (Franklin). Zoos' Print Journal 15(6): 269-274.

Ramanujam, M.E. (2003). Inter-specific intimidatory behaviour in nestling Indian Eagle Owls Bubo bengalensis (Franklin). Zoos' Print Journal 18(10): 1213-1216.

Ramanujam, M.E. (2004). Inter-specific intimidatory behaviour of adult Indian Eagle Owls Bubo bengalensis (Franklin) in defense of their nestlings. Zoos' Print Journal 19(2): 13431345.

Ramanujam, M.E. (2007). A catalogue of auditory and visual communicatory traits in the Indian Eagle Owl Bubo bengalensis (Franklin, 1831). Zoos' Print Journal 22(8): 2771-2776.

Vyas (1996). Checklist of the birds of the Delhi region: an update. Journal of the Bombay Natural History Society 93: 229. 